\title{
Lidocaine protects against renal and hepatic dysfunction in septic rats via downregulation of Toll-like receptor 4
}

\author{
JINBO LIU $^{1}$, HAOHUA ZHANG ${ }^{2}$, ZONGCAI QI $^{1}$ and XIUYING ZHENG ${ }^{1}$ \\ ${ }^{1}$ Department of Anesthesiology, Weifang People's Hospital; ${ }^{2}$ Department of Anesthesiology, \\ Brain Branch of Weifang People's Hospital, Weifang, Shandong 261041, P.R. China
}

Received April 5, 2013; Accepted September 27, 2013

DOI: $10.3892 / \mathrm{mmr} .2013 .1799$

\begin{abstract}
The present study was designed to determine the renoprotective and hepatoprotective effect of lidocaine in septic rats through the Toll-like receptor 4 (TLR4) signaling pathway. Adult male Sprague-Dawley rats were randomly divided into the following three groups: control, sepsis model and $10 \%$ lidocaine. A model of sepsis was established by injection of lipopolysaccharide (LPS; $5 \mathrm{mg} / \mathrm{kg}$ ) into the intraperitoneal cavity of rats. The same volume of saline was injected intraperitoneally into rats of the control group instead of LPS. Light microscopy was used to observe structural changes of the hepatic and nephridial tissues. qPCR was used to measure TLR4 mRNA expression levels and the protein expression was detected by flow cytometry. Western blotting was used to measure myocardial nuclear factor $\kappa \mathrm{B}(\mathrm{NF}-\kappa \mathrm{B})$ protein levels and ELISA was used to measure the levels of interleukin-6 (IL-6) in hepatic and nephridial tissues. The results demonstrated that $10 \%$ lidocaine treatment markedly decreased hepatic and nephridial injury in septic rats and inhibited the expression levels of TLR4, NF- $\mathrm{BB}$ and IL-6, which were upregulated in the sepsis model. In addition, the results indicated that lidocaine protects against renal and hepatic dysfunction in septic rats, which may be mediated by the downregulation of TLR4 and associated signaling molecules and inhibition of the inflammatory response.
\end{abstract}

\section{Introduction}

Sepsis is a major cause of multiple organ dysfunction syndromes (MODS) in intensive care units $(1,2)$. It is associated with the development of acute multiorgan dysfunction, morbidity and mortality and great increases in treatment expenditure. Sepsis

Correspondence to: Dr Xiuying Zheng, Department of Anesthesiology, Weifang People's Hospital, 151 Guangwen Street, Weifang, Shandong 261041, P.R. China

E-mail: zxywf01@126.com

Key words: lipopolysaccharide, Toll like receptor 4, interleukin-6, systemic inflammatory response syndrome, sepsis, lidocaine is usually initiated by microbial agents or their products, such as lipopolysaccharide (LPS), an outer membrane component of gram-negative bacteria. Sepsis induces a rapid release of inflammatory mediators, including tumor necrosis factor $\alpha$ $(\mathrm{TNF}-\alpha), \gamma$ interferon, interleukin-1 $\beta$ (IL-1 $\beta$ ) and interleukin-6 (IL-6) $(3,4)$, which leads to systemic inflammatory response syndrome (SIRS), MODS and mortality. When SIRS results in MODS and organ failure, the mortality becomes higher and may be $>50 \%$ (4-6).

Local anesthetics have been shown to modulate inflammatory cascades (7) and provide protection from ischemic reperfusion injury in the heart $(8)$, lung $(9,10)$ and liver $(11)$. Local anesthetics are capable of exerting anti-inflammatory effects on various cell types, including monocytes, macrophages and neutrophils (7). Lidocaine has been used as a traditional local anesthetic in medicine for $>100$ years. In addition to its anesthetic properties, lidocaine has been shown to attenuate inflammatory responses in vivo and in vitro and to possess anti-inflammatory and -infective effects. Lidocaine may also significantly improve the survival of mice and rats suffering from endotoxic shock (12) and protect them against liver and renal injury resulting from cecal ligation and puncture-induced septic peritonitis (13). Although lidocaine is crucial for immune function and inflammation, the mechanisms involved in its action are poorly understood.

Toll-like receptors (TLRs) recognize distinct microbial components that initiate the innate and adaptive immune responses. TLR activation culminates in the expression of appropriate proinflammatory and immunomodulatory factors to meet pathogenic challenges. Toll-like receptor 4 (TLR4), the first TLR found in mammals, is important for regulating the immune response and inflammatory reaction $(14,15)$. Stimulation of TLR4 by pathogens activates signal transduction pathways that lead to the induction of a range of antimicrobial genes and inflammatory cytokines (16).

In the present study, the mechanisms of whether the protective effects of lidocaine against LPS-induced renal and hepatic dysfunction in sepsis are associated with the activities of the TLR4 signaling pathway and nuclear factor $\kappa \mathrm{B}(\mathrm{NF}-\kappa \mathrm{B})$ were explored in vivo. Establishment of a rat model of sepsis that produced sepsis characterized by an initial hyperinflammatory response through lidocaine treatment was attempted in order to assess the relevance between the anti-inflammatory effects of lidocaine-based drugs and their mechanism of action. The 
results showed that lidocaine modifies the inflammatory response induced by LPS and affects the outcome from sepsis, which may be via inhibition of the TLR4 signaling pathway and inflammatory response.

\section{Materials and methods}

Materials. Lidocaine (10\%) was donated by Shanghai Chaohui Pharma Ltd. (Shanghai, China). TLR4 and NF- $\kappa B$ antibodies were purchased from Santa Cruz Biotechnology, Inc. (Santa Cruz, CA, USA). qPCR kits were purchased from Takara Bio, Inc. (Otsu, Japan) and IL-6 ELISA kit was purchased from Mai Biotechnology Institute (Hangzhou, China).

Animal care and treatment. Male Sprague-Dawley (SD) rats (SPF grade; 220-250 g) were provided by the Shanghai Jiaotong University Medical School (SHSMU; Shanghai, China). The procedures for experiments and animal care were approved by the Institutional Animal Care and Use Committee of SHSMU and conformed to the Guide for the Care and Use of Laboratory Animals by the National Institutes of Health (NIH Publication no. 80-23). Animals were maintained under standard laboratory conditions at $22-30^{\circ} \mathrm{C}$ and normal photoperiod (12-h dark/light). Adult male SD rats $(n=30)$ were randomly divided into the following three groups: control, sepsis model and $10 \%$ lidocaine $(5 \mathrm{mg} / \mathrm{kg})$. The sepsis models were established by injection of LPS $(5 \mathrm{mg} / \mathrm{kg})$ into the intraperitoneal cavity of rats. The same volume of saline was injected intraperitoneally (i.p.) into rats of the control group instead of LPS The lidocaine group of rats were treated with $10 \%$ lidocaine through tail vein injection, once every $2 \mathrm{~h}$ continuously for $24 \mathrm{~h}$ following LPS (the administration times were calculated according to the half-time of lidocaine). The rats were then anesthetized with pentobarbital ( $30 \mathrm{mg} / \mathrm{kg}$; i.p.). All the rats were handled at $24 \mathrm{~h}$ as follows: i) the right eyeball of each model rat was removed to collect a $3 \mathrm{ml}$ blood sample for biochemical tests; and ii) rats were sacrificed, the abdominal cavity was rapidly opened and the appropriate liver and kidney tissues extracted for subsequent examinations.

Blood tests. Venous blood (3 ml) was collected from animals in all the groups. Serum was prepared and stored in aliquots at $-70^{\circ} \mathrm{C}$ prior to analysis. Serum concentrations of aspartate aminotransferase (AST), alanine aminotransferase (ALT), creatinine $(\mathrm{Cr})$ and blood urea nitrogen $(\mathrm{BUN})$ were determined using a Hitachi Automatic Biochemical Analyzer (Hitachi High-Technologies Corporation (Tokyo, Japan). according to the manufacturer's instructions.

Hematoxylin and eosin $(H \& E)$ staining. Tissue blocks were collected randomly from the liver, lungs and kidneys, fixed with $4 \%$ paraformaldehyde for $\sim 12 \mathrm{~h}$ and embedded with wax. Coronal sections $(4 \mu \mathrm{m})$ were dewaxed, stained with H\&E and examined under light microscopy for histological changes. Digital images were captured.

qPCR detection of TLR4 mRNA expression. Total RNA from the liver and kidney samples was isolated with TRIzol reagent (Invitrogen, Carlsbad, CA, USA) according to the manufacturer's instructions. Reverse transcription was carried out using a RevertAid First Strand cDNA Synthesis kit (Qiagen, Hilden, Germany) and the resultant single strand cDNA was stored at $-20^{\circ} \mathrm{C}$ for later use in the PCR reactions. qPCR was performed by application of the $\mathrm{SYBR}^{\circledR} \mathrm{ExScript}^{\circledR} \mathrm{RT}$-PCR kit (Takara Bio, Inc. , Otsu, Japan) and using a two-step PCR reaction under the following conditions: $95^{\circ} \mathrm{C}$ for $10 \mathrm{sec}, 95^{\circ} \mathrm{C}$ for $5 \mathrm{sec}$ and 40 cycles at $60^{\circ} \mathrm{C}$ for $30 \mathrm{sec}$. $\beta$-actin was used as the housekeeping gene, according to Gene Bank in TLR4 and $\beta$-actin (NM_019178 and NM_001101.3). The primers used were: TLR4 forward, 5'-AGCCATTGCTGCCAA CATCA-3' and reverse, 5-ATGCAGGGGTTCTGG-3' (148 bp); and $\beta$-actin forward, 5'-CCCATCTATGAGGGTT ACGC-3' and reverse, 5'-TTTAATGTCACGCACGATTTC-3' (150 bp). TLR4 mRNA levels were calculated based on the $2^{-\Delta \Delta \mathrm{Ct}}$ method.

Flow cytometry. Suitable liver and kidney samples were transferred into flat plates with Hank's solution and ground into single cells with a homogenizer. The single cell suspension was filtered with 200 holes grit and cells were centrifuged twice with Hank's solution at 1,000 rpm for $10 \mathrm{~min}$. The supernatant solution was discarded and $0.5 \mathrm{ml}$ distilled water was added for $20 \mathrm{sec}$, rapidly followed by the addition of $1 \mathrm{ml}$ sodium chloride solution (1.7\%) and mixed. Hank's solution $(8 \mathrm{ml})$ was added and cells were centrifuged at 1,000 rpm for $10 \mathrm{~min}$. The cellular sediment was resuspended in Hank's solution. The cell survival rate was detected by trypan blue stain and the cell number was adjusted to $2 \times 10^{7} / \mathrm{ml}$ with Hank's solution. TLR4 antibody $(0.5 \mu \mathrm{g})$ was added into the $100 \mu \mathrm{l}$ cell suspension, incubated in a dark room at $4^{\circ} \mathrm{C}$ for $30 \mathrm{~min}$ and then PBS $(\mathrm{pH}$ 7.2-7.4) was added to a total volume to $0.5 \mathrm{ml}$. The cell suspension was mixed gently and then the cells were detected by flow cytometry (Becton-Dickinson, Franklin Lakes, NJ, USA).

Western blotting. Liver and kidney sample lysates were prepared by sonication using a RIPA buffer solution with protease inhibitor (Roche Diagnostics, Indianapolis, IN, USA). Extracts were centrifuged at 12,000 x g and the supernatant was retained. Protein concentrations were determined using the BCA Protein Assay kit (Pierce Biotechnology Inc., Rockford, IL, USA). Prior to loading, $2.5 \% \beta$-mercaptoethanol and $0.0125 \%$ bromophenol blue were added and lysates were boiled for $5 \mathrm{~min}$. The lysed protein was separated by $12 \%$ sodium dodecyl sulfate polyacrylamide gel electrophoresis and transferred onto PVDF membranes (Millipore, Billerica, MA, USA) by wet transfer at $200 \mathrm{~mA}$ and $4^{\circ} \mathrm{C}$ for $2 \mathrm{~h}$. The membrane was blocked with $5 \%(\mathrm{w} / \mathrm{v})$ non-fat milk in Tris-buffered saline $/ 0.05 \%$ Tween $(\mathrm{v} / \mathrm{v})$ for $2 \mathrm{~h}$ and incubated with the following primary antibodies at $4^{\circ} \mathrm{C}$ overnight: anti-NF- $\mathrm{KB}$, 1:1,000; or anti- $\beta$-actin, 1:1,000 (as control). The membranes were incubated with the proper radish peroxidase-conjugated secondary antibody at room temperature for $1 \mathrm{~h}$. Immunoblots were visualized using an enhanced chemiluminescence detection kit (Pierce Biotechnology, Inc.).

IL-6 measurement. Liver and kidney tissues were prepared and organized in a UP-200H ultrasounic homogenizer (Hielscher Ultrasonics $\mathrm{GmbH}$, Teltow, Germany). The homogenized liquid was centrifuged at 4,000 rpm for $15 \mathrm{~min}$. The rat IL-6 ELISA kit (Mai Biotechnology Institute) was used for detection according to the manufacturer's instructions. 

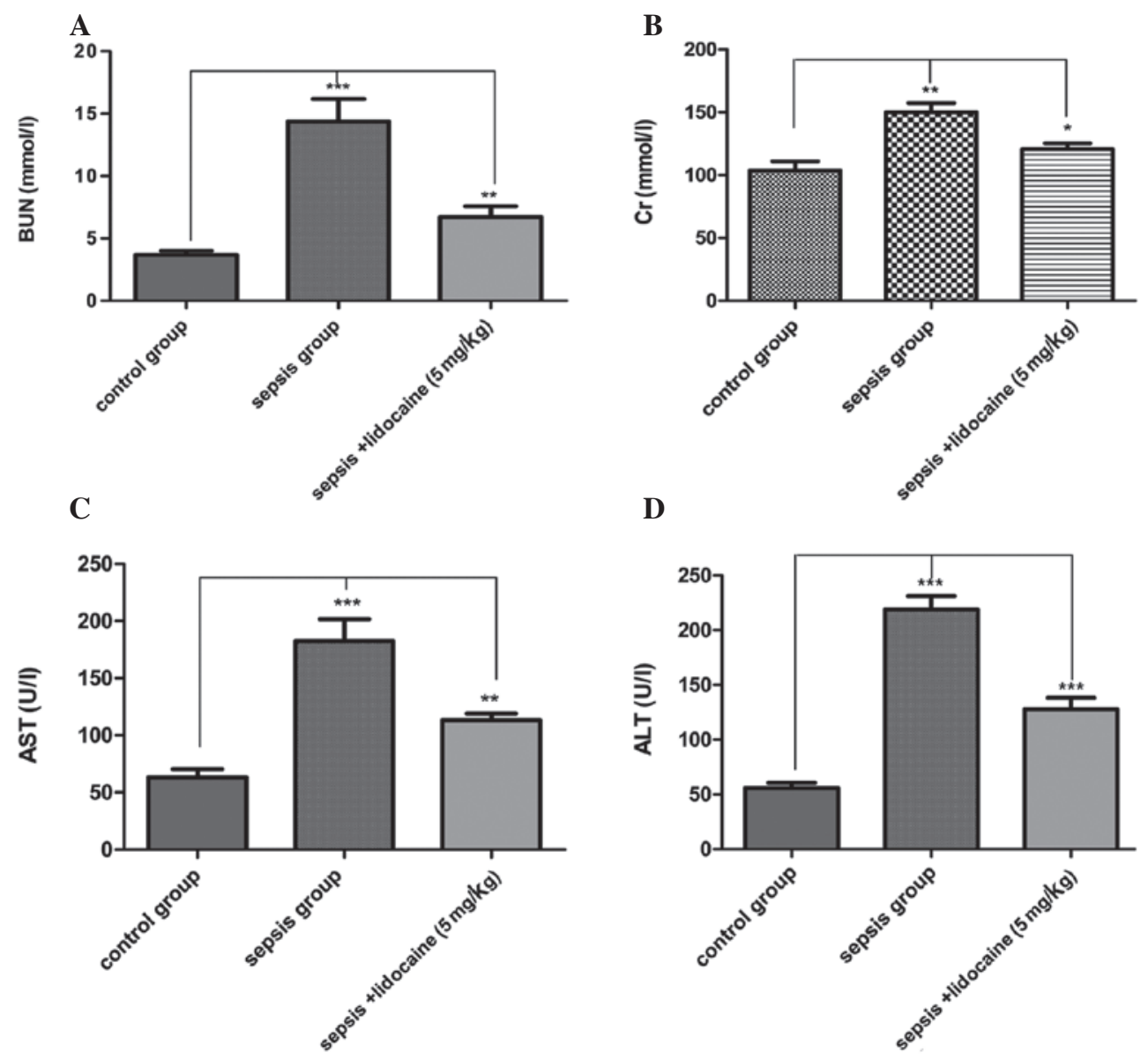

Figure 1. Serum concentrations of major blood biochemical parameters. (A) BUN, (B) Cr, (C) AST and (D) ALT as determined, are shown in the various treatment groups. Statistical significance between groups has been indicated." $\mathrm{P}<0.05,{ }^{* * *} \mathrm{P}<0.01,{ }^{* * * *} \mathrm{P}<0.001$. BUN, blood urea nitrogen; Cr, creatinine; AST, aspartate aminotransferase; ALT, alanine aminotransferase.

Statistical analysis. Data are expressed as mean \pm SEM. Comparisons of data between groups were made using a two-sample t-test, assuming equal variances. $\mathrm{P}<0.05$ was considered to indicate a statistically significant difference. All data were analyzed using SPSS 10.0 software (SPSS, Inc., Chicago, IL, USA).

\section{Results}

Lidocaine reduces mortality and protects renal and hepatic injury in septic rats. To determine whether lidocaine reduces mortality and protects renal and hepatic injury in septic rats, mortality was first assessed in all the groups. By the end of the experiment, all 10 rats had survived in the control group. However, the 5th and 1st rat in the LPS-induced sepsis and lidocaine groups, respectively, had died. Compared with the sepsis group, the mortality rate was significantly lower in the lidocaine group. To evaluate changes in the cellular integrity and functionality of the organs in the various groups, blood tests were performed for renal and hepatic function following sepsis by measuring plasma AST, ALT, Cr and BUN concentrations. For all the parameters tested, the values were significantly elevated in the LPS-induced sepsis group compared with those of the control group of animals. However, lidocaine treatment evidently blocked this elevation in the
LPS-induced sepsis group of animals (Fig. 1A-D). To validate LPS-induced organ damage, the histological changes were examined in the renal and hepatic tissue of the various groups. No apparent degeneration or necrosis was observed in the control groups. However, injury to the liver and kidneys was serious in the sepsis groups. In the kidneys, nephron atrophy was observed with a large number of proximal tubular epithelial cells with edema in the renal cortex (Fig. 2A and B). In the liver, narrowed hepatic central veins, sinusoidal dilatation, congestion, hepatocyte karyopyknosis and necrotic lesions with signs of hepatocyte atrophy were observed in the sepsis groups (Fig. 2D and E). No significant improvements of histopathology were identified with the application of lidocaine. Renal and hepatic cells lined up sequentially, cell membrane integrity remained and reduced necrosis or other pathological changes were detected (Fig. 2C and F). These results indicated that lidocaine reduces mortality and ameliorates renal and hepatic injury in septic rats induced by LPS.

Lidocaine decreases renal and hepatic TLR4 expression in septic rats. Although lidocaine reduces mortality and protects renal and hepatic injury in septic rats induced by LPS, the mechanisms of whether the protective effects of lidocaine in sepsis are associated with the TLR4 signaling pathway were explored.In the liver of animals, the expression of TLR4 mRNA 




Figure 2. Histopathological changes in the liver and kidney of animals in the various groups. Representative images of H\&E staining are shown of the following groups: (a and d) control; (b and e) sepsis; and (c and f) lidocaine-treated (magnification, x200). H\&E, hematoxylin and eosin.

A



B

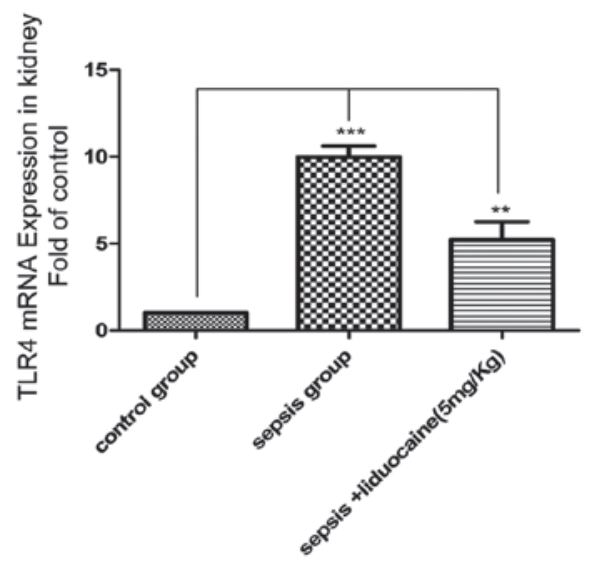

Figure 3. Expression of TLR4 mRNA in the (A) liver and (B) kidney of animals is shown in the various treatment groups. Data are expressed as fold over the quantitative values of the mRNA expression levels of the control group. Statistical significance between groups has been indicated; ${ }^{*} \mathrm{P}<0.05,{ }^{* *} \mathrm{P}<0.01$, ${ }^{* * * *} \mathrm{P}<0.001$. TLR4, Toll-like receptor 4 .

in the LPS-induced sepsis group was found to be significantly increased when compared with that of the control group, but this increase was markedly eliminated with lidocaine treatment (Fig. 3A). The changes of TLR4 mRNA expression were also found in the kidneys (Fig. 3B), further confirming the determination of the protein levels of TLR4 in the various treatment groups (Fig. 4A and B). These results demonstrated that lidocaine protects against renal and hepatic dysfunction in septic rats via the downregulation of TLR4, indicating that lidocaine may act on the TLR4 signaling pathway.

Lidocaine inhibits $N F-\kappa B$ expression in sepsis. The signal transduction pathway of TLR4 mediated by myeloid differentiation factor 88 (MyD88)-dependent pathways activating $\mathrm{NF}-\kappa \mathrm{B}$ is clearly understood. This in turn activates a wide variety of genes responsible for the synthesis of pro- and anti-inflammatory cytokines $(17,18)$. To confirm whether $\mathrm{NF}-\kappa \mathrm{B}$, an important signaling molecule associated with the TLR4 signaling pathway, is involved in the protection of lidocaine in sepsis, NF- $\kappa \mathrm{B}$ levels in the liver and kidneys of animals were detected in the various groups. Western blotting demonstrated that the expression of the $\mathrm{NF}-\kappa \mathrm{B}$ protein increased markedly in the sepsis groups compared with that of the control group, which was inhibited significantly with lidocaine treatment (Fig. 5A and B). These results showed that lidocaine inhibited $N F-\kappa B$ activation and that it is involved in the protection of lidocaine in sepsis.

Lidocaine significantlyattenuates proinflammatory IL-6 levels in renal and hepatic tissues in LPS-induced sepsis. TLR4 and $\mathrm{NF}-\kappa \mathrm{B}$ are considered important for the protection of lidocaine in sepsis, however, there has been no direct confirmation that 


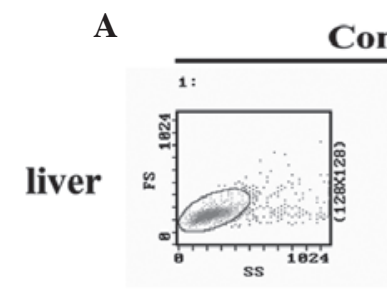

Control



2: A
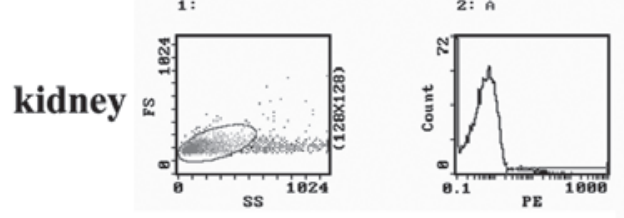

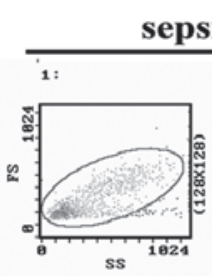

sepsis group
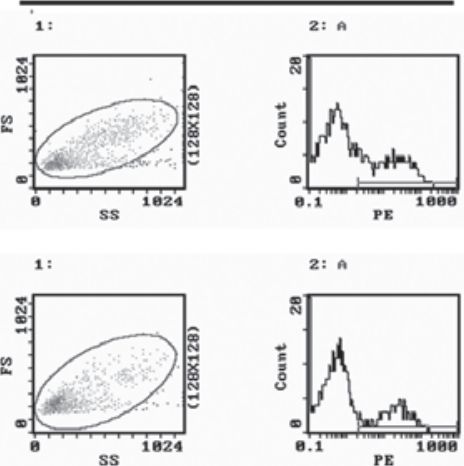
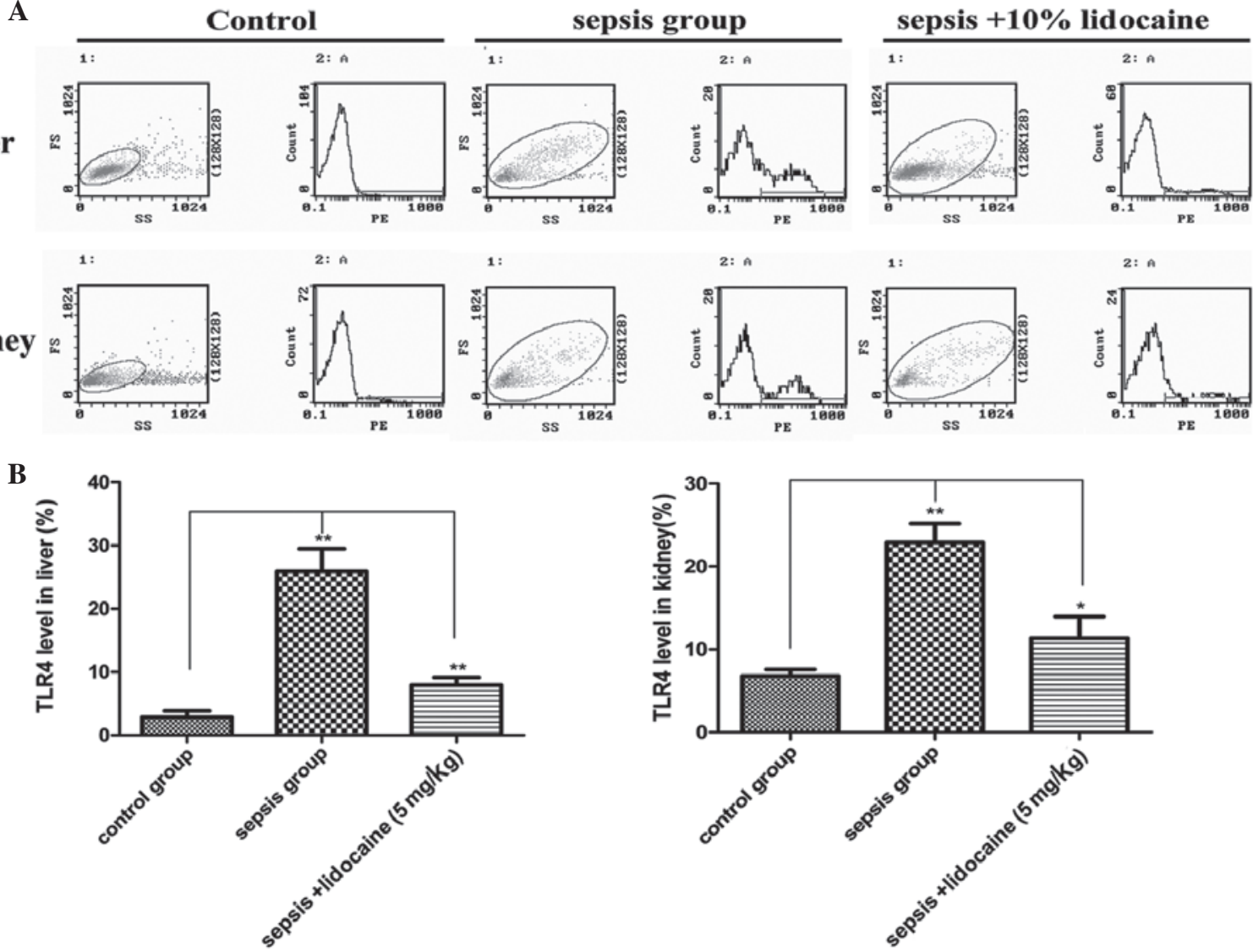

Figure 4. Protein levels of TLR4 in the liver and kidney of animals in the various groups determined by (A) flow cytometry and (B) quantitative values Statistical significance between groups has been indicated. ${ }^{*} \mathrm{P}<0.05,{ }^{* *} \mathrm{P}<0.01,{ }^{* * *} \mathrm{P}<0.001$. TLR4, Toll-like receptor 4.
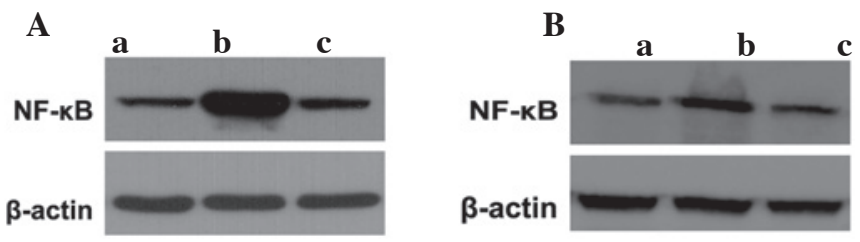

Figure 5. Expression of NF- $\mathrm{KB}$ protein in the (A) liver and (B) kidney of animals are shown in the various treatment groups; lanes a, control; b sepsis; and $\mathrm{c}$, lidocaine-treated. NF-кB, nuclear factor $\kappa \mathrm{B}$.
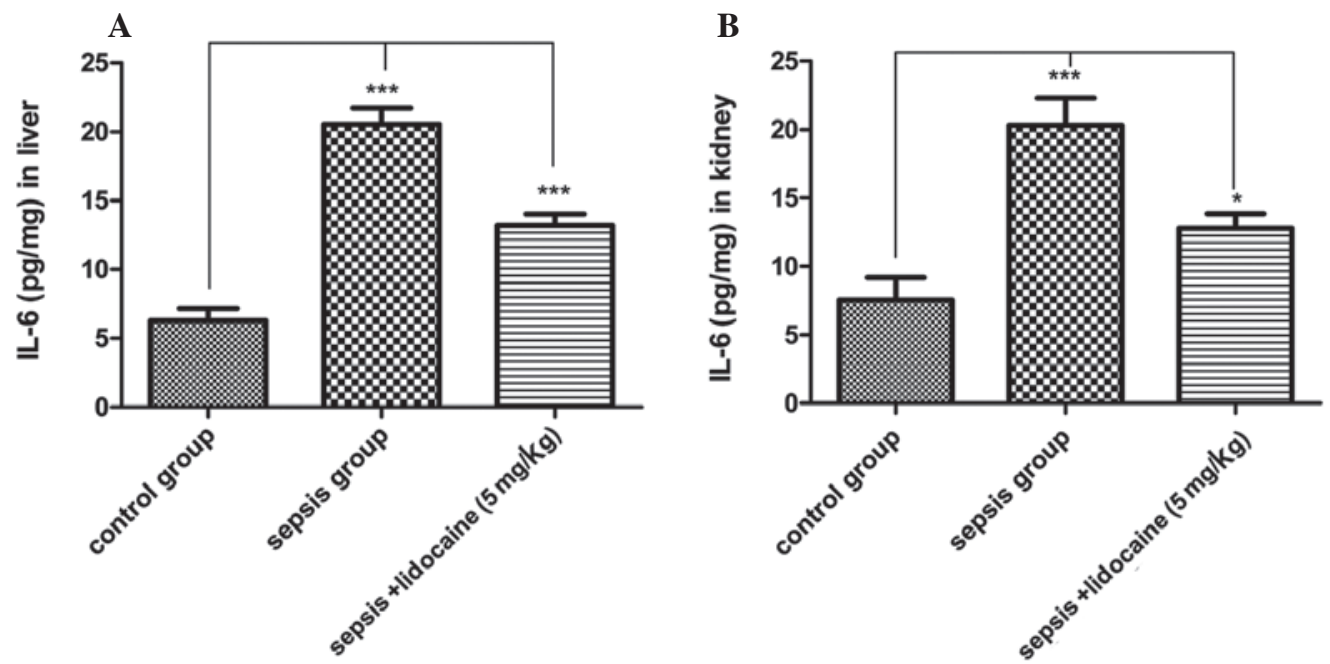

Figure 6. Expression of IL-6 in the (A) liver and (B) kidney of animals is shown in the various treatment groups. Statistical significance between groups has been indicated. ${ }^{*} \mathrm{P}<0.05,{ }^{* *} \mathrm{P}<0.01,{ }^{* * *} \mathrm{P}<0.001$. IL-6, interleukin- 6 . 
lidocaine decreases the release of pro-inflammatory cytokines in sepsis. Therefore, the levels of IL-6 protein were detected in the liver and kidneys of animals in the various groups. As predicted for the TLR4 signaling pathway, the levels of IL-6 in the sepsis group were significantly increased compared with those of the control group, whereas, this increase was notably eliminated with lidocaine treatment in the liver (Fig. 6A) and kidneys (Fig. 6B) of animals. These results demonstrated that lidocaine significantly attenuates proinflammatory IL-6 levels in the liver and kidneys in LPS-induced sepsis via inhibition of the TLR4 signaling pathway.

\section{Discussion}

The results of the current study have demonstrated that there is a complete TLR4-NF- $\kappa$ B proinflammatory cytokine signaling pathway involved in the pathological process of renal and hepatic injury in sepsis. Lidocaine provides significant protection from acute renal and hepatic dysfunctions and attenuates the hyperinflammatory response associated with rat sepsis induced by LPS via the inhibition of the TLR4-NF- $\mathrm{B}$ proinflammatory cytokine signaling pathway.

The most important pathogenic mechanism underlying sepsis is immune deregulation (19). TLRs are pathogen-associated molecular pattern recognition molecules that are crucial for innate immunity as the first defense system against microbial infection (20). TLR4, the first TLR found in mammals, is presented mainly by polymorphonuclear leukocytes, monocytes, macrophages and dendritic cells $(21,22)$, as well as various other cell types, including epithelial and endothelial cells (23-25). Different TLRs recognize various pathogen-associated molecular patterns, with TLR4 mediating the response to LPS from gram-negative bacteria (26-28). The signal transduction pathway of TLR4 is mainly mediated by MyD88-dependent pathways to activate NF- $\kappa \mathrm{B}$ (29). NF- $\kappa \mathrm{B}$ is one of the most important regulators of proinflammatory gene expression. During inflammation, $N F-\kappa B$ regulates the transcription of proinflammatory genes and enzymes under signals received by TLRs (30-32). The stimulation of TLR4 by LPS induces the release of critical proinflammatory cytokines that are necessary to activate potent immune responses (33-36).

Based on the experimental results of the present study, we hypothesized that TLR4/NF- $\mathrm{B}$ may be involved in the inhibition process of lidocaine in sepsis. To address this possibility, LPS was introduced to establish the septic model. The amount of renal and hepatic cell surface TLR4 protein increased the sensitivity of cells to LPS. Lidocaine almost completely blocked LPS-triggered NF- $\kappa \mathrm{B}$ activation in renal and hepatic tissues in sepsis. This demonstrated the functional involvement of TLR4 in the signal transduction pathway of lidocaine in LPS-induced sepsis. Thus, it appeared that the TLR4-dependent signaling pathway is involved in lidocaine-induced inhibitory effects. TLR antagonists have previously been found to block components of the immune response that are necessary to ward off subsequent infection and to overcome the septic state (37). Moreover, TLR4-deficient mice were hyporesponsive to LPS $(38,39)$. Previously, Johnson et al have shown that the ability of heparin sulfate and pancreatic elastase to induce SIRS is greatly reduced in TLR4-mutant mice, indicating that SIRS may be induced by signaling through TLR4. These results from transgenic mice highlighted further support for a contribution of specific TLRs to the pathogenesis of SIRS (40).

Synthesis of cytokines, including TNF- $\alpha$, IL- $1 \beta$ and IL-6, are mediated by NF- $\kappa \mathrm{B}$ and the current study found that lidocaine inhibited LPS-induced IL- 6 production and downregulated TLR4 and NF-кB. Thus, we hypothesized that the $N F-\kappa B$ signaling pathway is involved in the lidocaine-mediated signaling pathway. Stimulus-induced $\mathrm{NF}-\kappa \mathrm{B}$ activity is the central mediator of inflammatory responses. LPS-stimulated NF- $\kappa \mathrm{B}$ transcription activity was investigated in all groups. It was found that NF- $\mathrm{NB}$ transcription activity was increased significantly following treatment with LPS in sepsis, which was inhibited by lidocaine. We hypothesized that the lidocaine-induced anti-inflammatory response is involved in signaling mediated by the $\mathrm{NF}-\kappa \mathrm{B}$ signaling pathway.

It is well known that mortality in sepsis is markedly affected by the development of organ injury and dysfunction (41). There exists ample evidence of the potent anti-inflammatory effects of lidocaine $(13,42)$. In a previous rabbit model of lung injury, Takao et al demonstrated that lidocaine injection decreased various chemotactic factors, which resulted in reduced neutrophil infiltration (43). In a separate study, lidocaine and bupivacaine inhibited the release of inflammatory mediators leukotriene B4 and interleukin-1 from human neutrophils and monocytes (44). In concordance, the present study showed that lidocaine injection not only decreased mortality in LPS-induced sepsis, but also significantly reduced the magnitude of renal and hepatic injury. Lidocaine has the ability to decrease Cr, BUN, ALT and AST, indicating that the protection conferred by lidocaine is global and not restricted to a particular organ. IL-6 is a prototypic example of a proinflammatory cytokine that is important for propagating a host of secondary inflammatory cascades. The current study has demonstrated that lidocaine injection resulted in a marked decrease in circulating concentrations of IL- 6 in septic rats.

Overall, investigating TLR4/NF- $\kappa \mathrm{B}$-regulated proinflammatory cytokine and enzyme expression is a good strategy for novel anti-inflammatory drug development. Lidocaine may decrease renal and hepatic tissue TLR4 expression and provide global protection from organ injury and dysfunction resulting from sepsis. The exploration of the protective function of lidocaine to sepsis and its mechanism has great significance in the field of emergency medicine.

\section{References}

1. Wang $\mathrm{H}$ and $\mathrm{Ma} \mathrm{S}$ : The cytokine storm and factors determining the sequence and severity of organ dysfunction in multiple organ dysfunction syndrome. Am J Emerg Med 26: 711-715, 2008.

2. Dewar DC and Balogh ZJ: The epidemiology of multiple-organ failure: a definition controversy. Acta Anaesthesiol Scand 55: 248-249, 2011.

3. Dinarello CA: Proinflammatory and anti-inflammatory cytokines as mediators in the pathogenesis of septic shock. Chest 112: S321-S329, 1997.

4. Cohen J: The immunopathogenesis of sepsis. Nature 420: 885-891, 2002

5. Brun-Buisson C: The epidemiology of the systemic inflammatory response. Intensive Care Med 26 (Suppl 1): S64-S74, 2000.

6. Angus DC and Wax RS: Epidemiology of sepsis: an update. Crit Care Med 29: S109-S116, 2001.

7. Hollmann MW and Durieux ME: Local anesthetics and the inflammatory response: a new therapeutic indication? Anesthesiology 93: 858-875, 2000 
8. Strohm C, Barancik T, Bruhl ML, Kilian SA and Schaper W: Inhibition of the ER-kinase cascade by PD98059 and UO126 counteracts ischemic preconditioning in pig myocardium. J Cardiovasc Pharmacol 36: 218-229, 2000.

9. Das KC and Misra HP: Prevention of reperfusion lung injury by lidocaine in isolated rat lung ventilated with higher oxygen levels. J Postgrad Med 49: 17-20, 2003.

10. Schmid RA, Yamashita M ando K, Tanaka Y, Cooper JD and Patterson GA: Lidocaine reduces reperfusion injury and neutrophil migration in canine lung allografts. Ann Thorac Surg 61: 949-955, 1996.

11. Tomori H, Shiraishi M, Koga H, et al: Protective effects of lidocaine in hepatic ischemia/reperfusion injury in vitro. Transplant Proc 30: 3740-3742, 1998

12. Fuentes JM, Talamini MA, Fulton WB, Hanly EJ, Aurora AR and De Maio A: General anesthesia delays the inflammatory response and increases survival for mice with endotoxic shock Clin Vaccine Immunol 13: 281-288, 2006.

13. Gallos G, Jones DR, Nasr SH, Emala CW and Lee HT: Local anesthetics reduce mortality and protect against renal and hepatic dysfunction in murine septic peritonitis. Anesthesiology 101: 902-911, 2004.

14. Kawai T and Akira S: TLR signaling. Cell Death Differ 13 816-825, 2006

15. Akira S: TLR signaling. Curr Top Microbiol Immunol 311: $1-16,2006$

16. Compton T, Kurt-Jones EA, Boehme KW, et al: Human cytomegalovirus activates inflammatory cytokine responses via CD14 and toll-like receptor 2. J Virol 77: 4588-4596, 2003

17. Tanimura N, Saitoh S, Matsumoto F, Akashi-Takamura S and Miyake K: Roles for LPS-dependent interaction and relocation of TLR4 and TRAM in TRIF-signaling. Biochem Biophys Res Commun 368: 94-99, 2008.

18. Kawai T and Akira S: The role of pattern-recognition receptors in innate immunity: update on toll-like receptors. Na Immunol 11: 373-384, 2010

19. Rittirsch D, Flierl MA and Ward PA: Harmful molecular mechanisms in sepsis. Nat Rev Immunol 8: 776-787, 2008.

20. Akira S and Hemmi H: Recognition of pathogen-associated molecular patterns by TLR family. Immunol Lett 85 : $85-95$, 2003.

21. Muzio M, Bosisio D, Polentarutti N, et al: Differential expression and regulation of toll-like receptors (TLR) in human leukocytes: selective expression of TLR3 in dendritic cells. J Immunol 164: 5998-6004, 2000.

22. O'Neill LAJ and Bowie AG: The family of five: TIRdomain-containing adaptors in toll-like receptor signalling. Nat Rev Immunol 7: 353-364, 2007.

23. Zhang FX, Kirschning CJ, Mancinelli R, et al: Bacterial lipopolysaccharide activates nuclear factor-kappaB through interleukin-1 signaling mediators in cultured human dermal endothelial cells and mononuclear phagocytes. J Biol Chem 274: 7611-7614, 1999.

24. Cario E, Rosenberg IM, Brandwein SL, Beck PL, Reinecker HC and Podolsky DK: Lipopolysaccharide activates distinct signaling pathways in intestinal epithelial cell lines expressing toll-like receptors. J Immunol 164: 966-972, 2000.

25. Faure E, Equils O, Sieling PA, et al: Bacterial lipopolysaccharide activates NF-kappaB through toll-like receptor 4 (TLR-4) in cultured human dermal endothelial cells Differential expression of TLR-4 and TLR-2 in endothelial cells. J Biol Chem 275: 11058-11063, 2000.

26. Underhill DM, Ozinsky A, Smith KD and Aderem A: Toll-like receptor-2 mediates mycobacteria-induced proinflammatory signaling in macrophages. Proc Natl Acad Sci USA 96 14459-14463, 1999.
27. Ozinsky A, Underhill DM, Fontenot JD, et al: The repertoire for pattern recognition of pathogens by the innate immune system is defined by cooperation between toll-like receptors. Proc Natl Acad Sci USA 97: 13766-13771, 2000.

28. Poltorak A, He X, Smirnova I, et al: Defective LPS signaling in $\mathrm{C} 3 \mathrm{H} / \mathrm{HeJ}$ and $\mathrm{C} 57 \mathrm{BL} / 10 \mathrm{ScCr}$ mice: mutations in Tlr4 gene. Science 282: 2085-2088, 1998.

29. Ahn KS, Sethi G and Aggarwal BB: Nuclear factor-kappa B: from clone to clinic. Curr Mol Med 7: 619-637, 2007.

30. Lu YC, Yeh WC and Ohashi PS: LPS/TLR4 signal transduction pathway. Cytokine 42: 145-151, 2008.

31. Hoffmann A, Natoli G and Ghosh G: Transcriptional regulation via the NF-kappaB signaling module. Oncogene 25: 6706-6716, 2006.

32. Hoffmann A, Levchenko A, Scott ML and Baltimore D: The IkappaB-NF-kappaB signaling module: temporal control and selective gene activation. Science 298: 1241-1245, 2002.

33. Couture LA, Piao W, Ru LW, Vogel SN and Toshchakov VY: Targeting toll-like receptor (TLR) signaling by toll/interleukin-1 receptor (TIR) domain-containing adapter protein/MyD88 adapter-like (TIRAP/Mal)-derived decoy peptides. J Biol Chem 287: 24641-24648, 2012.

34. Fitzgerald KA, Palsson-McDermott EM, Bowie AG, et al: Mal (MyD88-adapter-like) is required for toll-like receptor-4 signal transduction. Nature 413: 78-83, 2001

35. Gray P, Dunne A, Brikos C, Jefferies CA, Doyle SL and O'Neill LA: MyD88 adapter-like (Mal) is phosphorylated by Bruton's tyrosine kinase during TLR2 and TLR4 signal transduction. J Biol Chem 281: 10489-10495, 2006.

36. Verstak B, Nagpal K, Bottomley SP, Golenbock DT, Hertzog PJ and Mansell A: MyD88 adapter-like (Mal)/TIRAP interaction with TRAF6 is critical for TLR2- and TLR4-mediated NF-kappaB proinflammatory responses. J Biol Chem 284: 24192-24203, 2009.

37. Brown KL, Cosseau C, Gardy JL and Hancock RE: Complexities of targeting innate immunity to treat infection. Trends Immunol 28: 260-266, 2007.

38. Hoshino K, Takeuchi O, Kawai T, et al: Cutting edge: toll-like receptor 4 (TLR4)-deficient mice are hyporesponsive to lipopolysaccharide: evidence for TLR4 as the Lps gene product. J Immunol 162: 3749-3752, 1999.

39. Arbour NC, Lorenz E, Schutte BC, et al: TLR4 mutations are associated with endotoxin hyporesponsiveness in humans. Nat Genet 25: 187-191, 2000

40. Johnson GB, Brunn GJ and Platt JL: Cutting edge: an endogenous pathway to systemic inflammatory response syndrome (SIRS)-like reactions through Toll-like receptor 4. J Immunol 172: 20-24, 2004

41. Angus DC, Linde-Zwirble WT, Lidicker J, Clermont G, Carcillo J and Pinsky MR: Epidemiology of severe sepsis in the United States: analysis of incidence, outcome and associated costs of care. Crit Care Med 29: 1303-1310, 2001.

42. Li CY, Tsai CS, Hsu PC, Chueh SH, Wong CS and Ho ST: Lidocaine attenuates monocyte chemoattractant protein-1 production and chemotaxis in human monocytes: possible mechanisms for its effect on inflammation. Anesth Analg 97: 1312-1316, 2003.

43. Takao Y, Mikawa K, Nishina K, Maekawa N and Obara H: Lidocaine attenuates hyperoxic lung injury in rabbits. Acta Anaesthesiol Scand 40: 318-325, 1996

44. Sinclair R, Eriksson AS, Gretzer C, Cassuto J and Thomsen P: Inhibitory effects of amide local anaesthetics on stimulus-induced human leukocyte metabolic activation, LTB4 release and IL-1 secretion in vitro. Acta Anaesthesiol Scand 37: $159-165,1993$. 